\title{
Investigating the Degree of Satisfaction with Municipal Managers: A Case Study in Iran
}

\author{
Mehdi Momeni ${ }^{1} \&$ Mohammadreza Asadi Astaraki ${ }^{1}$ \\ ${ }^{1}$ Faculty of Literature and Humanities, Najafabad Branch, Islamic Azad University, Najafabad, Isfahan, Iran \\ Correspondence: Mehdi Momeni, Faculty of Literature and Humanities, Najafabad Branch, Islamic Azad \\ University, Najafabad, Isfahan, Iran. E-mail: Momeni100@gmail.com
}

\author{
Received: April 17, 2014 Accepted: June 24, 2014 Online Published: July 24, 2014 \\ doi:10.5539/ass.v10n16p42 URL: http://dx.doi.org/10.5539/ass.v10n16p42
}

\begin{abstract}
One of the main goals of public organizations is gaining clients' satisfaction. In this regard, paying attention to clients' satisfaction and in general citizens of each city is of great importance for public organizations specifically the municipality which has an outstanding role in communication and services that it offers to the residents of each city. The main goal of this study is spatial analysis of investigating the degree of the citizen's satisfaction with the municipal's managers in regions of Najaf Abad city, Iran. The research is descriptive-analytic and the data was gathered by library-field research (questionnaire) method. After data collection and data analysis and testing the hypotheses by SPSS software, the results of the research showed that the citizens' and residents' satisfaction in different regions is at a low level.
\end{abstract}

Keywords: investigation, satisfaction, municipal managers, Najafabad city, Iran

\section{Introduction}

Municipality is a public non-governmental organization which has independence and legal entity and is established under the supervision of the city council which is elected by people and government through the country ministry in order to perform duties and tasks stipulated in the municipality's law (Saeednia, 2004). Management is the art and knowledge of directing and harmonizing or synchronizing people's efforts and implementing these efforts for reaching an organization's goals (Jasbi, 2010). Civil management in a broad concept includes a wide range of activities and is the most important part of offering civil public services and this kind of management must bring about the people's satisfaction in a society from an organization in which the people or citizens observe requirements of goodness (Ansari, 2003). Satisfaction with an organization refers to the degree of coordination of expectations and realities (Zivyar et al., 2010).

Improving performance for increasing efficiency and effectiveness is considered as a main goal in different levels of management. Innovative approach of public organizations about efficiency and effectiveness has also experienced a radical transformation. One of the most important criteria for evaluating performance is the citizen's satisfaction with civil services. Satisfaction indexes can have different dimensions in public sectors which are beyond the customer's attitude to a product or service in a private sector (Riahee, 2002). The effectiveness of public organizations in society's quality and conditions makes investigating their social functions inevitable. This research not only provides a clear picture of the quality of services to those who receive them especially in public organization's performance but also is one of the effective factors in forming social resources and trust to public organizations. Citizens' satisfaction with civil services is a crucial factor in generating motivation in citizens for participating in civil development and improving the quality of their life environment while dissatisfaction with these organizations and perceiving discrimination in giving civil services in different regions leads to citizens' pessimism, frustration, distrust, disappointment, lack of responsibility and eventually lack of participation and cooperation.

In this study, the effect of diverse factors on citizens' satisfaction including providing services, managers' attention and consideration and their performance is presented in the form of 30 closed questions. First, the research's hypotheses and then the literature, materials and method, the necessities of the research, data, figures, hypothesis testing, conclusion, and suggestions are provided. 


\section{Hypotheses}

- There is a significant relationship between provided services by the municipality and citizens' satisfaction.

- There is a relationship between the municipal managers' performance on improving civil quality and the residents' satisfaction.

- There is a relationship between the municipal managers' consideration to the city residents' opinions and needs and citizens' satisfaction.

\section{Literature Review}

Ipsos (2009) obtained the following results in a research about the degree of satisfaction of Canadian citizens in Calgary city. Sixty-eight percent of citizens in Calgary had satisfaction with civil services offered. This amount was $64 \%$ in 2007 and 2008. 7\% were unsatisfied and the rest were partly unsatisfied, moderate, and partly satisfied.

Gooharipoor et al. in a survey research about evaluating the performance of civil management based on citizens' satisfaction with civil services in Tehran city came to the conclusion that the level of satisfaction in the two regions of Tehran (the south and the north regions) was close to moderate and it was lower in the south region.

In 2008, America Barometer Institute gave a report about evaluating the citizens' satisfaction with the municipal services in 22 countries with the population of 33809 individuals. According to this report, the citizens in Brazil, Dominican, and Ecuador had the highest level of satisfaction. On the other hand, citizens in Blitz, Haiti, and Jamaica had the lowest level of satisfaction and it was neither good nor bad in Latin America. The results of the research show that individuals with higher income are more satisfied with city services than low-income people. Moreover, people who live in cities are more satisfied with offered services than people who live in rural areas and the level of satisfaction is more in women than men (Montalvo, 2009).

Bangladeshi researchers (2009) tried to evaluate the performance of the city council in Dhaka in providing services in a research with a sample of 360 participants using a questionnaire. The research is centered on three responsibilities of the city including the management of recycling waste materials, controlling insects, and issuing licenses. The results show that the citizens' satisfaction with the management of recycling waste materials and issuing different licenses and certificates is at an intermediate level. The level of satisfaction in some regions is very high and in some other regions is very low. In addition, the research showed that the economic and social indexes of respondents to the questionnaire have a great effect on their opinions, the more the level of income, the more the satisfaction of citizens (Akther \& Islam, 2009).

Ansari (1983) evaluated the level of satisfaction of clients referring to management and planning organization in Isfahan province and the ways to increase it using a questionnaire. The population included 40 administrative organizations, 135 administrative or office companies, members of university faculties, students of universities in the province, 356 contractors, and etc. He came to this conclusion that the level of satisfaction is at an intermediate level and more.

In 1994, the first report was published about the level of citizens' satisfaction with city services in Columbus city in the United States. In 2002, this report was based on phone interviews done randomly with a sample of 1188 citizens. The results showed that the highest level of satisfaction was with firefighting and the lowest with garbage gathering.

In 2009, the level of satisfaction of citizens was evaluated by SRC center in Wisconsin University. It sent questionnaires by e-mail randomly to citizens of Columbus city which comprised the sample including 1137 citizens. This questionnaire had 6 sections of questions according to the city comprehensive plan: transportation, natural and cultural resources, housing, economic development and land use, social services and facilities, and local government. This aim of this plan was gathering the views of residents about better fulfillment of the city's comprehensive plan. The obtained results revealed that the citizens requested the improvement of the quality of roads and sidewalks and pavements, better management of rain water, and favorite projects of communities and are willing to pay tax for them. The citizens also requested the promotion of the housing quality and having diverse choice of selection for dwelling in the city (Janke \& Hedley, 2009).

Scott et al. did a research in Australia about the role of participation and attachment in satisfaction with the services of local governments. The sample was 3000 individuals and the research was done using a questionnaire. The results showed that participation and attachments of citizens has a direct relationship with satisfaction with the services of local governments and on average most of residents and citizens are satisfied with government services. 
Mohammadifar et al. (2009) did a research about trusting government organizations and the level of citizens' satisfaction in Kermanshah. The sample consisted of 8352 individuals in 51 governmental organizations and units. Using a questionnaire, they came to the conclusion that trust has a significant effect on the level of clients' satisfaction and for improving trust; standardizing and increasing the sensibility and keenness of managers and employees are recommended.

In 2009, Gutiérrez et al. conducted a research about dimensions of quality in public sector: the municipal services and citizens' perception in 76 local governments in Spain with the population of 400 individuals who were individually interviewed. They reached the conclusion that there is a direct relationship between the quality of services and satisfaction, while there is an indirect relationship between quality and credit. Moreover, they found that there is a strong relationship between satisfaction and credit.

Rafeeian et al. (2007) evaluated the citizens' satisfaction in Navab region in Tehran with the population of 270 individuals using a questionnaire. The citizens' satisfaction was found to be at an intermediate level. There were six factors constituting satisfaction of citizens with residential complexes. Among these factors, residents were satisfied only with the security of the complexes, neighbors' relationships was at an intermediate level and they did not have satisfaction with other factors (facilities, sanitation, view, physical features).

Hajinejad et al. (2008) conducted a survey on the citizens' satisfaction with the new modern and the old historic context of Shiraz city. They found that the citizens' satisfaction with the quality of the environment was below an intermediate or average level and there is little difference among the residents' satisfaction in the old context of the city.

Bidokhti et al. (2006) evaluated the degree of customer-orientation in administrative organizations in Semnan province by means of a questionnaire. The sample consisted of 7455 individuals in 87 administrative organizations and found that satisfaction is at a high level.

Zivyar et al. (2010) evaluated the clients' satisfaction with administrative organizations in Isfahan province by using a questionnaire. The sample was 10000 individuals in 51 public and governmental organizations. They concluded that the index of necessary facilities such as Xerox or copy machine, water dispenser, ... etc. was nearly $10 \%$ lower than the overall index and the indexes of courtesy, employees' respect and politeness, was $6 \%$ more than the overall index.

\section{Materials and Method}

This research was designed based on three hypotheses and in the form of 30 closed questions. The method of the research was descriptive-analytic and the data was gathered based in library-field research (questionnaire) method. For evaluating the reliability and validity of the questionnaire, first 30 questionnaires were distributed among citizens of Najafabad city in a pilot study primarily. The Chronbach Alpha was suitable and it was approved by the experts; therefore, using Cochran formula

$$
\left[n=\frac{\frac{t^{2} p q}{d^{2}}}{1+\frac{1}{N}\left(\frac{t^{2} p q}{d^{2}}-1\right)}\right]
$$

The size of the sample was estimated to be 400 and the questionnaire was distributed randomly among the citizens who were over 20 years old in 3 age groups of 20-35, 36-50, and over 50 years old. They completed the questionnaire. Najafabad is divided into 4 regions according to the city limits, the population, and the areas around the city, namely the city center with 55\%, Yazdanshahr with $20 \%$, Amirabad with $18 \%$, and Vilashahr with $7 \%$ of population (Map 1). It was checked that the ratio of each of these regions of questionnaires is the same percentage (Iran Statistics Center, 2010). After the completion of questionnaires by the subjects, the reliability of the questions in the questionnaire Chronbach alpha was used again this was 0.86 showing that the questions are well-designed according to the subjects and experts' points of view. Also, after the completion of questionnaires, the data was analyzed by SPSS software.

\subsection{The Realm of the Research}

The study area was in Najafabaf city between the longitude of 51 degrees and 24 minutes and the width of 32 degrees and 38 minutes north latitude. The distance of Najafabad city center to the center of Isfahan city is about $30 \mathrm{~km}$ (comprehensive plan of Najaf Abad province, 2001) and the time of the survey was in 2013. 


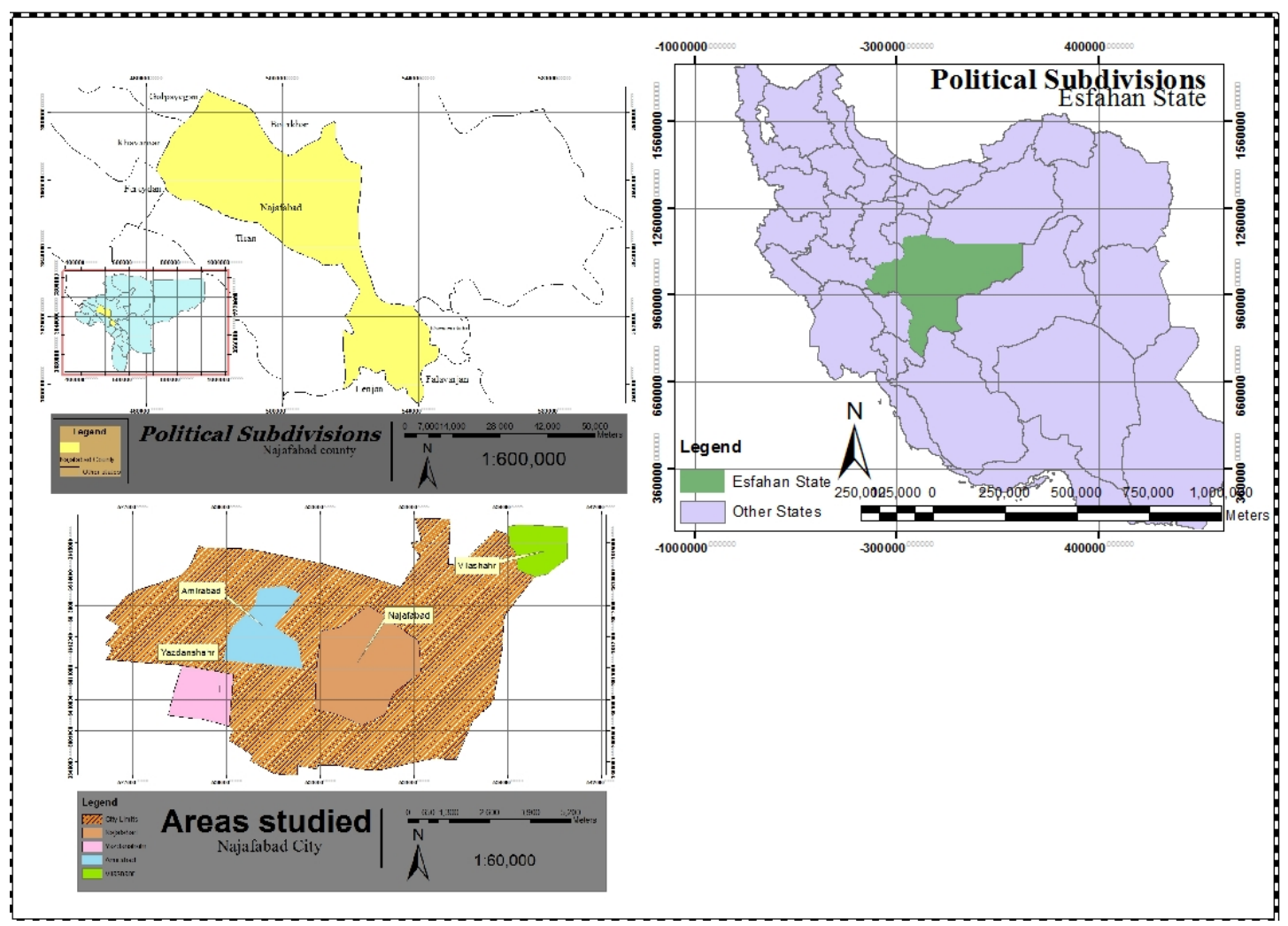

Figure 1. The realm of the research

\subsection{The Necessity of the Research}

Nowadays, paying attention to customer-orientation is regarded as one of the main social orientations. Recognizing organizations' performance and citizens' evaluations of them and attitudes towards them as social sub-systems is so important that some experts consider social change and evolution through organizational change and evolution as one of the main strategies for countries' development (Zivyar et al., 2010). The degree of clients' satisfaction determines the relative success of an organization's performance. Therefore, it is important to know how much the clients are satisfies is important and even it is more important to know how to keep them satisfied (Ansari, 2003). The success and failure of each organization in reaching its goals and performing its responsibilities relies on management which has one of the most important roles. If a city is considered as an organization, it is necessary for it to be leaded by an agent who has plans for the future and manages the current affairs (Saeednia, 2004). It is hoped that evaluating the degree of citizens' satisfaction with municipal managers and factors influencing satisfaction draws the attention of managers, decision makers, administrators, and citizens.

\section{Data Analysis}

\subsection{Descriptive Results of the Study}

Table 1 shows the gender composition of the subjects' distribution. In total, 339 men comprised $84 / 8 \%$, and 61 women comprised $15 / 2 \%$ of the subjects of the study.

Table 1. The frequency of the gender of respondents

\begin{tabular}{lll}
\hline Gender & Frequency & Percentage \\
\hline Male & 339 & $84 / 8$ \\
Female & 61 & $15 / 2$ \\
Total & 400 & 100 \\
\hline
\end{tabular}


Considering Table 2, studying the subjects' age shows that the most number of subjects that is $76 / 8 \%$ of respondents were between 20 to 35 years old, $17 / 4 \%$ of them were between 36 to 50 years old, and $5 / 8 \%$ was above 51 to 65 years old.

Table 2. The frequency of the age of respondents

\begin{tabular}{lll}
\hline Age & Frequency & Percentage \\
\hline $20-35$ & 307 & 76.8 \\
$36-50$ & 70 & 17.14 \\
$51-65$ & 23 & 5.8 \\
Total & 400 & 100 \\
\hline
\end{tabular}

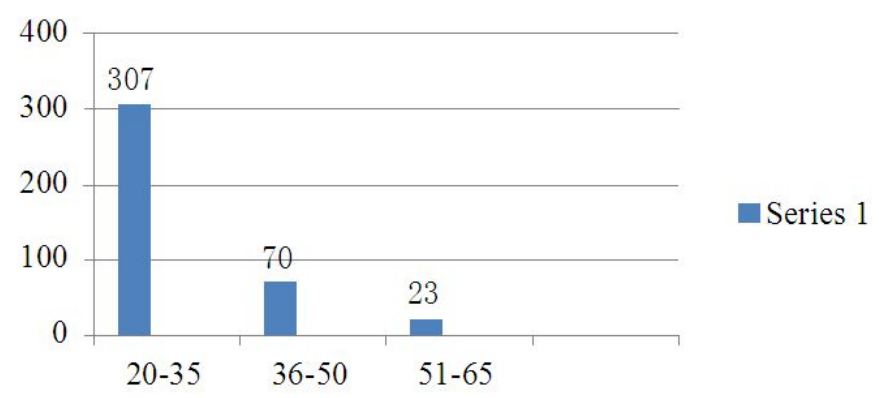

Figure 2. Respondents' age

As Table 3 shows, the majority of respondents that is $64 / 8 \%$ of them had bachelor and higher degrees, $14 \%$ had diploma, $11 \%$ had upper diploma degree, and 10/2\% had degrees below diploma level.

Table 3. Frequency of the level of education of the respondents

\begin{tabular}{lll}
\hline Education & Frequency & Percentage \\
\hline Below diploma & 41 & 10.2 \\
Diploma & 56 & 14 \\
Upper diploma & 44 & 11 \\
Bachelor and higher & 259 & 64.8 \\
Total & 400 & 100 \\
\hline
\end{tabular}

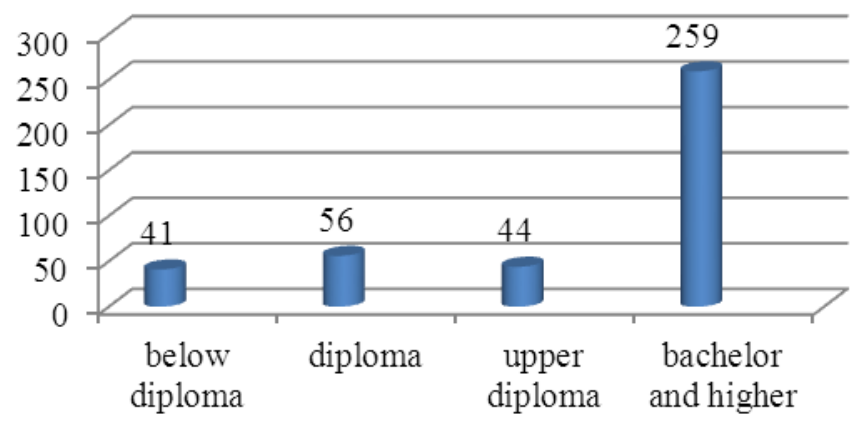

- Series 1

Figure 3. Frequency of the respondents' education 


\subsection{Inferential Results of the Study}

\section{Hypotheses testing}

Hypothesis 1: There is a significant relationship between provided services by the municipality and citizens' satisfaction.

Table 4. Relationship between municipal services and the citizens' satisfaction

\begin{tabular}{lllllll}
\hline The studied regions & Variable & T & degree of freedom & Sig & P value & Mean \\
\hline Najafabad & Managers' Services & 59.25 & 219 & $0 / 000$ & 0.05 & 2.21 \\
Yazdanshahr & Managers' Services & 54.44 & 79 & $0 / 000$ & 0.05 & 2.09 \\
Amirabad & Managers' Services & 28.45 & 75 & $0 / 000$ & 0.05 & 2.36 \\
Villashahr & Managers' Services & 42.82 & 23 & $0 / 000$ & 0.05 & 2.04 \\
\hline
\end{tabular}

The significance of the study which is .000 is less than the $\mathrm{P}$ value .05 . Therefore, the zero hypotheses (There is no significant relationship between provided services by the municipality and citizens' satisfaction) are rejected. As a result, it is concluded that there is a significant relationship between provided services by the municipality and citizens' satisfaction.

Hypothesis 2: There is a relationship between the municipal managers' performance on improving civil quality and the residents' satisfaction.

Table 5. Relationship between managers' performance in improving city quality and the residents' satisfaction

\begin{tabular}{lllllll}
\hline The studied regions & Variable & T & degree of freedom & Sig & P value & Mean \\
\hline Najafabad & Managers' Performance & 85.14 & 219 & $0 / 000$ & 0.05 & 2.46 \\
Yazdanshahr & Managers' Performance & 78.58 & 79 & $0 / 000$ & 0.05 & 2.46 \\
Amirabad & Managers' Performance & 40.39 & 75 & $0 / 000$ & 0.05 & 2.50 \\
Villashahr & Managers' Performance & 72.38 & 23 & $0 / 000$ & 0.05 & 2.46 \\
\hline
\end{tabular}

The significance of the study which is .000 is less than the $\mathrm{P}$ value .05 . Therefore, the zero hypotheses (There is no significant relationship between the municipal managers' performance and the citizens' satisfaction) are rejected. As a result, it is concluded that there is a relationship between the municipal managers' performance and the citizens' satisfaction.

Hypothesis 3: There is a relationship between the municipal managers' consideration to the city residents' opinions and needs and citizens' satisfaction.

Table 6. Relationship between managers' consideration of city residents' needs and the residents' satisfaction

\begin{tabular}{lllllll}
\hline The studied regions & Variable & T & degree of freedom & Sig & P value & Mean \\
\hline Najafabad & Managers' Consideration & 46.53 & 219 & $0 / 000$ & 0.05 & 2.10 \\
Yazdanshahr & Managers' Consideration & 39.53 & 79 & $0 / 000$ & 0.05 & 1.93 \\
Amirabad & Managers' Consideration & 22.29 & 75 & $0 / 000$ & 0.05 & 2.30 \\
Villashahr & Managers' Consideration & 30.40 & 23 & $0 / 000$ & 0.05 & 1.86 \\
\hline
\end{tabular}

The significance of the study which is .000 is less than the $\mathrm{P}$ value .05 . Therefore, the zero hypotheses are rejected. As a result, it is concluded that there is a relationship between the municipal managers' consideration to the city residents' opinions and needs and citizens' satisfaction.

\section{Discussion and Conclusion}

The success and failure of each organization in reaching its goals and performing its responsibilities relies on management which has one of the most important roles. If a city is considered as an organization, it is necessary for it to be leaded by an agent who has plans for the future and manages the current affairs. Municipality is a 
public non-governmental organization which has independence and legal entity and is established under the supervision of the city council which is elected by people and government through the country ministry in order to perform duties and tasks stipulated in the municipality's law. Considering this definition and comparing it with the obtained results, it can be said that Najafabad municipal managers were not successful in gaining the citizens' satisfaction.

The participation of $75 / 8 \%$ of respondents in the range of $20-35$ years old and $17 / 9 \%$ of them in the range of 36-50 years old represents the participation of the active stratum of the residents of the city in this study. Moreover the result that $64 / 8 \%$ of respondents had bachelor or higher degrees represents that they had thoughtful and professional opinions to the questions.

From the results of T-test of the hypotheses, it can be concluded that the degree or level of the citizens' satisfaction with the municipal managers in the 4 studied regions was low. In the first hypothesis in which the municipal managers' services to the citizens are evaluated, the lowest level of satisfaction belongs to Villashahr and Yazdanshahr (2/04, and 2/09) and the highest belongs to Amirabad and Najafabad (2/36, and 2/21).

In the second hypothesis in which the municipal managers' performance is evaluated, the lowest level of satisfaction belongs to Najafabad, Yazdanshahr, and Villashahr (2/46) and the highest belongs to Amirabad $(2 / 50)$.

In addition, in the third hypothesis in which the municipal managers' consideration is evaluated, the lowest level of satisfaction belongs to Villashahr and Yazdanshahr (1/86, and 1/93) and the highest belongs to Amirabad and Najafabad (10/30, and 2/2).

The results of this study reveal that the level of satisfaction is lower than intermediate in general and the lowest level of satisfaction belongs to Villashahr and Yazdanshahr and it is to some extent higher in Najafabad and Amirabad. It should be mentioned that the more the level of citizens' satisfaction, the higher the degree of participation and accompany with city management organization.

\section{References}

Akhter, M., Islam, I., \& Uddin Hasan, M. (2009). Evaluation of municipal services in selected wards of Dhaka City Corporation: Citizen's perspective. Bangladesh.

Aminbidokhti, A. (2007). Evaluating the degree of customer-orientation in administrative organizations in Semnan province (1st ed.). Development of management and human sources assistance office, Semnan.

Ansari, M. E. (2003). Evaluating the level of satisfaction of clients referring to management and planning organization in Isfahan province and the ways to increase it (1st ed.). Management and planning organization in Isfahan province, Isfahan.

Barakpoor, N., Goharipoor, H., \& Karimi, M. (2010). Evaluating municipalities' performance based on evaluating the citizens'satisfaction with city services (A case study: Regions 1 and 11 in Tehran). No. 25, Two city management journals, Tehran.

Hafeznia, M. (2002). An introduction to research method in human sciences (7th ed.). Samt publications, Tehran, Iran.

Hajinezhad, A., Rafeeian, M., \& Zamani, H. (2011). Studying and ranking influential factors on citizens' satisfaction with the quality of life environment (A case study: Comparing the new modern and old context in Shiraz city). No. 77, Human geography researches.

Ipsos. (2009). Citizen Satisfaction Survey, the City of Calgary. Canada.

Iran Statistics Center, Statistics Report. (2010).

Janke, J. (2009). Citizen Satisfaction Survey, Report to the City of Columbus. USA.

Jasbi, A. (2011). Principles and foundations of management (5th ed.). Hakimbashi publivations, Tehran, Iran.

Karimi, M., \& Goharipor, H. (2011). Evaluation of urban management performance based on citizen satisfaction with municipal services in city of Tehran. Singapore.

Mohammadifar, Y., Ahmadi, M., \& Hashemi, S. D. (2010). Trusting governmental organizations the level of citizens' satisfaction: A case study of administrative organizations in Kermanshah. Cultural researches scientific research journal, 3(3).

Montalvo, D. (2009). Citizen Satisfaction with Municipal Services. USA.

Najafabad province comprehensive plan. (2001). 
Rafeeian, M., Asgarizadeh, Z., \& Asgarizadeh, M. (2008). Evaluating the degree of quality of residential complexes with the focus of the citizens' satisfaction in Navab region. Human Sciences Teacher Journal, 1(14). Tehran

Riahee, B. (2002). The management of comprehensive quality in public sector. Iran industrial and education center (1st ed.). Tehran, Iran.

Rodríguez, P. G., Vázquez, B., Luis, J., Vaughan, R., \& Edwards, J. (2009). Quality dimensions in the public sector: Municipal services and citizen's perception. Spain.

Saeednia, A. (2004). City Management. The country's village and urban municipal organization publications, Tehran, Iran.

Scott, D., \& Vitartas, P. (2008). The role of involvement and attachment in satisfaction with local government services. Australia.

Zivyar, F., Hasanebrahimi, R., Aghili, N., \& Mohammadi, M. (2011). A review of the results of evaluating the clients'satisfaction with administrative organizations in Isfahan province (1st ed.). Nehzat publications.

\section{Copyrights}

Copyright for this article is retained by the author(s), with first publication rights granted to the journal.

This is an open-access article distributed under the terms and conditions of the Creative Commons Attribution license (http://creativecommons.org/licenses/by/3.0/). 